\title{
Calidad de leches crudas en sistemas doble propósito en Córdoba (Colombia), en condiciones de máxima y mínima precipitación
}

\section{Quality of raw milk in double purpose systems in Córdoba (Colombia), in maximum and minimum precipitation conditions}

Fecha de recepción: 17 de enero de 2015

Fecha de aprobación: 28 de mayo de 2015
Virginia Consuelo Rodríguez-Rodríguez ${ }^{1}$ Arles Ferney Acosta-Ruiz ${ }^{2}$ Alfonso Calderón-Rangel ${ }^{3}$

\begin{abstract}
Resumen
Una de las preocupaciones en la producción agropecuaria es la obtención de alimentos de óptima calidad e inocuos para el consumo humano. Se ha propuesto que una leche de excelente calidad debe presentar altos porcentajes de proteína, grasa y sólidos totales, así como bajos recuentos de mesófilos y de células somáticas, y estar libre de inhibidores, para asegurar su inocuidad. El objetivo de este estudio fue conocer la calidad fisicoquímica y el recuento de las células somáticas (RCS) en leches crudas provenientes de empresas ganaderas doble propósito en el departamento de Córdoba, Colombia, y comparar estos datos en periodos de máxima y mínima precipitación, para ver las diferencias fisicoquímicas y el RCS en cada época. Mediante un muestreo no probabilístico y un estudio descriptivo en época de máxima y mínima precipitación, se recolectaron muestras de leche cruda en 127 empresas ganaderas. Se determinaron los porcentajes de acidez, de grasa, de sólidos no grasos, de solidos totales y de células somáticas. Los datos obtenidos se analizaron por estadística descriptiva usando INFOSTAT. Estos valores se encontraron dentro de los parámetros normales, con variaciones en relación con la época en que se muestreó.
\end{abstract}

Palabras clave: Calidad de la leche, sanidad de la ubre, recuento de células somáticas (RCS).

1 M.Sc. Universidad de Córdoba (Monteria-Córdoba, Colombia).

2 Universidad de Córdoba (Monteria-Córdoba, Colombia).

3 M.Sc. Universidad de Córdoba (Monteria-Córdoba, Colombia). acalderonr@correo.unicordoba.edu.co. 


\begin{abstract}
A concern in agricultural production is to obtain optimal food quality and harmless for human consumption. It has been proposed that excellent quality milk must have high percentages of protein, fat, total solids and low counts of mesophilic, somatic cell-count (SCC) plus free of inhibitors to ensure their safety. The objective was to determine the physicochemical quality and udder health in raw milk, from dual purpose livestock companies in Córdoba Colombia, and at the same time, to compare these data with periods of high and minimal rainfall to see the physicochemical differences and udder health in each period. Using a non-probability sampling and descriptive study periods of maximum and minimum rainfall, raw milk samples were collected from 127 cattle enterprises. It was determined: the percentage of acidity, fat, nonfat solids, total solids and somatic cell count. The data obtained were analyzed using descriptive statistics INFOSTAT. These values were within the normal range, with variations related to the time it was sampled.
\end{abstract}

Key Words: Milk quality, udder health, somatic cell-count (SCC). 


\section{Introducción}

La tendencia mundial en la producción agropecuaria es la obtención de alimentos de excelente calidad e inocuos para el consumo humano, y las empresas ganaderas productoras de leche es el eslabón primario, en el que se debe empezar a garantizar las condiciones para obtener un producto de óptima calidad dentro de la cadena láctea (1).

Un estudio previo en Colombia ha propuesto que una leche de excelente calidad debe presentar mayores porcentajes de proteína $(3,2 \%)$, grasa $(3,5 \%)$ y sólidos totales $(12,2 \%)$, y recuentos inferiores de mesófilos (50000 UFC/ml) y células somáticas (100000 CS/ml) (1). La legislación colombiana establece que la leche para consumo humano debe ser libre de inhibidores o de sustancias extrañas y que se debe asegurar su inocuidad (2).

Las células somáticas (CS) son indicativas del grado de inflamación de las glándulas mamarias (mastitis) como consecuencia de la agresión de patógenos u otros factores de índole traumática $(3,4)$, y una de sus funciones es fagocitar y lisar los patógenos y eliminar deshechos del foco de infección mediante enzimas e inhibidores bacterianos como proteasas, lipasas y fosfolipasas; estas enzimas se incorporan a la leche, y posteriormente aceleran la descomposición de la proteína y la grasa y reducen la vida útil de los diferentes derivados lácteos $(5,6,7)$.

El recuento de células somáticas (RCS) es uno de los parámetros de mayor interés para determinar el estado sanitario de las ubres y la calidad de la leche (8). EI RCS en la leche aumenta en proporción directa con la severidad del cuadro infeccioso (4). En una leche libre de mastitis subclínica, el RCS es bajo $(<100000 \mathrm{CS} / \mathrm{ml})$. Por medio de un modelo de regresión lineal se determinó que a medida que aumenta la prevalencia de la mastitis en fincas se aumenta el RCS (9). También el incremento del RCS depende del patógeno causante de la mastitis (10).

Los cambios en la composición fisicoquímicas de la leche están influenciados por el RCS (11). Se ha reportado que mastitis subclínicas alteraron la composición de algunas variables fisicoquímicas la leche; por ejemplo, en vacas Gyr se redujo el contenido de lactosa (\% de lactosa), sólidos no grasos (\% SNG) y porcentaje de solidos totales (\% ST), pero no hubo diferencia cuando se comparó el contenido de proteína y grasa entre cuartos infectados y no infectados (10). Un estudio demostró que el rendimiento en la fabricación del queso costeño fue superior en un 5,8\% cuando se elaboró con leches de bajos RCS, en comparación con leches con altos RCS (12). Fuera de afectar los parámetros anteriormente mencionados, también se ha determinado que altos RCS, como consecuencia de la mastitis bovina, produjeron una disminución en la producción de leche de hasta un 15\% (13).

Además de establecer la calidad fisicoquímica de leches crudas manejadas bajo el sistema doble propósito en el departamento de Córdoba, el objetivo general de este trabajo fue comparar sus porcentajes de acidez, grasa, sólidos no grasos, sólidos totales, recuento de células somáticas y volumen de producción de leche en condiciones de máxima y mínima precipitación.

\section{Materiales y métodos}

Tipo de estudio. Se implementó un estudio descriptivo en época de máxima y mínima precipitación.

Lugar de estudio. Se realizó en ocho municipios del departamento de Córdoba, Colombia.

Tamaño de muestra. Se evaluaron 127 empresas ganaderas, que proveen a tres centros de acopio y procesadores de leche. Las 127 muestras de leche cruda, una por cada ganadería, fueron tomadas en época de máxima y de mínima precipitación. La procesadora 1 aportó el $51 \%$ de las muestras; la 2 , el $22 \%$, y la 3 , el $27 \%$. El total de vacas en ordeño fue de 4675, con un mínimo de 3 y un máximo de 220 vacas por finca; el volumen de producción por finca fluctuó entre 10 y $1010 \mathrm{~L}$.

Criterios de selección. Las empresas ganaderas se seleccionaron teniendo en cuenta su ubicación en el departamento de Córdoba y que sean manejadas bajo el sistema doble propósito; además, que se garantizara el consentimiento y la participación 
activa de los propietarios o administradores. Igualmente, se aplicó una encuesta sobre diferentes aspectos administrativos, de mercadeo, de manejo zootécnico y de infraestructura de las empresas ganaderas.

Toma de muestra. Como la gran mayoría de las empresas ganaderas almacenan la leche en cantinas u otros recipientes de plástico hasta la entrega a los transportadores, en cada una de las seleccionadas se tomó una muestra de leche de $200 \mathrm{ml}$, proveniente de cada uno de los recipientes de almacenamiento; con un agitador manual de acero inoxidable estéril se mezcló durante 3 o 4 minutos, y con un cucharón de acero inoxidable estéril se tomaron las submuestras $(25 \mathrm{ml})$, que se mezclaron en un recipiente estéril; de la sumatorias de las submuestras se colectó la muestra de leche de 200 $\mathrm{ml}$, que se identificó con un código previamente establecido. Donde la leche es almacenada en tanque refrigerado, se tomó, previa agitación por diez minutos, una muestra de $200 \mathrm{ml}$ de leche, usando un cucharón de acero inoxidable estéril. Todas las muestras se recolectaron en frascos estériles taparrosca azul, previamente rotulados, que se conservaron en refrigeración $\left(4^{\circ} \mathrm{C}\right)$, hasta su procesamiento en el Laboratorio de Lactología de la Facultad de Medicina Veterinaria y Zootecnia, de la Universidad de Córdoba, donde se implementó el análisis fisicoquímico y el RCS; las muestras se procesaron en menos de 24 horas después de su recolección.

Determinación de parámetros fisicoquímicos. La determinación de los parámetros fisicoquímicos se hizo por duplicado y se sacaron los respectivos promedios; se tomó la cantidad en litros por cada finca, teniendo en cuenta los registros de las empresas de acopio, y estos promedios se compararon por época de máxima y mínima precipitación.

La acidez se evaluó por la titulación con una solución de hidróxido de sodio $0,1 \mathrm{~N}$, y el resultado se informó como porcentaje de ácido láctico (\% de a. láctico) (14). El porcentaje de grasa (\% de Grasa) se determinó por el método de Gerber, método volumétrico con el que la grasa de la leche es separada de las proteínas por acción del ácido sulfúrico y usando alcohol amílico y centrifugación como fa- cilitadores; de esta forma el contenido de grasa es leído directamente en un butirómetro especial calibrado (15). El porcentaje de sólidos no grasos (\% SNG) se determinaron con el usó del refractómetro de Bertuczi (16), para ello la velocidad de propagación de la luz se relaciona directamente con los sólidos disueltos en agua, y el porcentaje de los sólidos totales (\% ST), por el método de la estufa, que corresponde al residuo expresado como porcentaje obtenido después de efectuada la desecación de la leche (14).

Determinación de la sanidad de la ubre. EI RCS se realizó mediante determinación fluorescente, con el contador óptico de células, que emplea yoduro de propidio (17).

Análisis de resultados. Toda la información recolectada de las empresas ganaderas fue manejada bajo estricta confidencialidad. Los datos se recolectaron mediante un formulario estandarizado y fueron tabulados en una hoja electrónica. Se realizó un análisis descriptivo de las variables fisicoquímicas y de los recuentos de mesófilos y células somáticas. La comparación de los promedios de máxima y mínima precipitación se hizo por la prueba de t de Student, con una significancia $(p \leq$ 0.05). El software implementado para el análisis estadístico fue INFOSTAT.

\section{Resultados y discusión}

El ordeño manual predominó en el 99,33\% de las empresas ganaderas, desempeñado en su totalidad por hombres; el 96,64\% de las fincas cuentan con establo destinado para el ordeño, pero sólo el $59,06 \%$ estaban cubiertos y el $40,94 \%$ parcialmente cubiertos. Los pisos del lugar destinado para el ordeño fue cemento $(41,62 \%$ de las fincas) y tierra $(58,38 \%)$. Solamente el $2,01 \%$ de las empresas cuentan con tanque de refrigeración; el 99,33\% filtran la leche con: colador plástico $(56,08 \%)$, filtro desechable $(36,49 \%)$, tela $(4,05 \%)$, colador metálico $(2,03 \%)$ y filtro desechable en línea $(1,35 \%)$, que correspondió a fincas con ordeño mecánico.

De las 127 empresas ganaderas, sólo el 52,34\% implementaron la prueba del CMT, y el $58,38 \%$ no cuentan con programas de prevención y con- 
trol de la brucelosis, ni el $80,53 \%$, de tuberculosis bovina, enfermedades de control oficial y que las empresas ganaderas deben atender como parte de las buenas prácticas ganaderas, como política sanitaria para ser más atractiva su adopción $(18,19)$. Al evaluar el manejo que le dan a la leche procedente de vacas que reciben tratamiento con antibióticos, el $78,52 \%$ no las ordeñan y se deja a los terneros, el $8,05 \%$ se les suministra a animales de compañía (caninos y gatos), el 5,36\% descarta la leche, el $8,05 \%$ la vende y el $0,67 \%$ fue para autoconsumo humano.
La acidez en las dos épocas evaluadas fue del $0,15 \%$ de ácido láctico, valor que se encuentra dentro de los rangos normales establecidos en la legislación colombiana para leches crudas; no se encontró diferencia entre las muestras evaluadas (Tabla I), contrario a lo reportado para la sabana de Sucre, donde se encontraron valores superiores en época de verano, los cuales, según los autores, pueden deberse a factores como falta de refrigeración de la leche, almacenamiento en recipientes no apropiados, prologado tiempo de transporte de la leche y alta temperatura de la zona (20).

Tabla I. Comparación de parámetros fisicoquímicos y de células somáticas en leches crudas en máxima y mínima precipitación.

\begin{tabular}{|c|c|c|c|c|c|}
\hline VARIABLE & $\begin{array}{c}\text { MÍNIMA } \\
\text { PRECIPITACIÓN }\end{array}$ & $\begin{array}{c}\text { DESVIACIÓN } \\
\text { ESTANDART }\end{array}$ & $\begin{array}{c}\text { MÁXIMA } \\
\text { PRECIPITACIÓN }\end{array}$ & $\begin{array}{c}\text { DESVIACIÓN } \\
\text { ESTANDART }\end{array}$ & $\begin{array}{c}\text { DECRETO } \\
\mathbf{6 1 6} / \mathbf{2 0 0 6}\end{array}$ \\
\hline Acidez (\% de a. láctico) & $0,15^{\mathrm{a}}$ & 0,03 & $0,15^{\mathrm{a}}$ & 0,02 & $0,13-0,17 \%$ \\
\hline$\%$ Grasa & $3,92^{\mathrm{a}}$ & 0,54 & $3,93^{\mathrm{a}}$ & 0,55 & Mayor a $3,00 \%$ \\
\hline$\% \mathrm{SNG}$ & $8,94^{\mathrm{a}}$ & 0,43 & $8,88^{\mathrm{b}}$ & 0,33 & Mayor a $8,30 \%$ \\
\hline$\% \mathrm{ST}$ & $11,44^{\mathrm{a}}$ & 0,98 & $11,96^{\mathrm{b}}$ & 0,72 & $\begin{array}{c}\text { Mayor a } \\
11,30 \%\end{array}$ \\
\hline RCS (CS/mL) & $370315^{\text {a }}$ & 237632 & $450165^{\mathrm{b}}$ & 286481 & No aplica \\
\hline Producción (L/Día) & $8510^{\mathrm{a}}$ & 83,36 & $14520^{\mathrm{b}}$ & 123,22 & No aplica \\
\hline
\end{tabular}

Valores seguidos por letras iguales en la misma fila no difieren significativamente $(P \leq 0,05)$.

El promedio del porcentaje de grasa fue de 3,92\% para la época de mínima precipitación y de 3,93\% para la época de máxima precipitación, es decir, no se presentaron diferencias significativas por época (Tabla I), pero estos promedios están por encima del $3 \%$ establecido en la legislación colombiana (2), y pueden deberse al uso de cruces cebuínos con Bos taurus (21).

Los promedios para los $\%$ de SNG fueron de $8,94 \%$ para la época mínima precipitación y de 8,88\% para la época de máxima precipitación; se estableció que existen diferencias significativas cuando se comparan las épocas (Tabla I). Previamente se ha reportado un valor de 8,59\% para SNG en leches de la zona del Sinú (Colombia). También, los valores determinados en el actual estudio son superiores al $8,7 \%$ establecido para leches de excelente calidad (1). En el estado de Sao Paulo (Brasil) no se determinó efecto significativo de la época del año sobre la composición química, debido a la suplementación, a la mayor disponibilidad y a calidad de los forrajes (22). En Mexico, los \% de SNG no mostraron diferencias significativas de acuerdo con las épocas de máxima y mínima precipitación (23). Se ha demostrado que para disminuir el efecto de la época del año sobre la concentración de los sólidos se debe manipular la proporción de los forrajes con el concentrado, el nivel de fibra en la ración y la frecuencia de alimentación, así como minimizar el estrés calórico (24).

Se determinaron diferencias significativas entre las épocas de máxima y mínima precipitación para el $\%$ de ST (Tabla I); los promedios fueron de 11,44\% y de $11,96 \%$ para mínima y máxima precipitación, respectivamente; estos promedios están dentro del rango establecido para leches de buena calidad (1). En México no se encontraron diferencias significativas en el \% de ST en épocas de máxima y mínima 
precipitación (23). Valores de 12,79 y $13,11 \%$ del $\%$ de ST han sido reportados en las Sabanas de Sucre (Colombia) en épocas de mínima y máxima precipitación, respectivamente (20), lo cual podría ser explicado por la mayor disponibilidad y calidad de la oferta forrajera para las vacas en ordeño en los periodos de máxima precipitación (25).

Un RCS normal en leche de tanque debe ser menor o igual a $250.000 \mathrm{CS} / \mathrm{mL}(26,27)$; esto puede indicar que hasta un $6 \%$ de los cuartos se encuentran infectados (26). RCS menor a $200.000 \mathrm{CS} / \mathrm{mL}$ son buenos, pero menores a $100.000 \mathrm{CS} / \mathrm{mL}$ son ideales o excelentes (28). Actualmente, valores de corte para RCS de tanque con relación siguen en discusión (29). Los promedios de RCS en mínima y máxima precipitación están por encima de los valores anteriormente mencionados, y fueron de 370315 y de $450165 \mathrm{CS} / \mathrm{ml}$, en época de mínima y máxima precipitación, respectivamente, lo que indica que hay una alta prevalencia de mastitis y que los productores deben implementar planes preventivos de manejo; estas diferencias fueron significativas (Tabla I); este mayor promedio en la época de máxima precipitación indica que hay mayor predisposición a que se creen condiciones adversas en caminos (lodazales) y a que por malas prácticas de manejo y poca higiene que se tienen haya un aumento en el número de casos de mastitis y de RCS.

Para Montería (Colombia) se ha reportado un promedio del RCS de $345.133 \mathrm{CS} / \mathrm{mL}$ en las muestras de leche (9), valor parecido al descrito en este estudio. Un RCS normal en leche de tanque debe ser menor o igual a $250.000 \mathrm{CS} / \mathrm{mL}(26,27)$, lo que indicaría que hasta un $6 \%$ de los cuartos se encuentran infectados (26).

Altos RCS y de mesófilos durante la pasteurización liberan enzimas proteolíticas que pueden disminuir la vida útil de los productos y derivados lácteos en las góndolas de los supermercados (1, 7), y disminuyen las diferentes fracciones de las características fisicoquímicas, reduciendo la productividad de la leche cuando se somete a los métodos de coagulación (9). EI RCS se incrementa en la leche en relación directa con el grado de daño del agente infeccioso, por lo que su determinación constituye una de las medidas de mayor beneficio para establecer el estado sanitario de la ubre y la calidad de la leche (8).

Para medir la diferencia de producción en litros se tomaron como referencia los registros de entrega de las empresas de acopio (Tabla I); así, en época de lluvias el volumen en litros de leche entregados por día fue de 14.520, con un promedio de 114 litros por empresa ganadera, mientras que en la época seca fue de 8.510 litros de leche día, con un promedio de 67,01 litros por empresa ganadera; estas diferencias fueron significativas y pueden deberse a la abundancia de pastos en la época de Iluvias (21), que determina lo que se conoce como estacionalidad de la producción. Resultados muy similares señalan que en la época de lluvias hay un aumento significativo de 750 a 900 litros (30). Igualmente, vacas que iniciaron su lactancia en la época de transición verano-invierno obtuvieron mayores producciones de leche que las que empezaron lactancia en época seca (31).

\section{Conclusiones}

En cuanto a la calidad fisicoquímica de las variables evaluadas, se estableció que las leches manejadas en el sistema doble propósito en la región de Córdoba (Colombia) son de muy buena calidad, con una variación dependiendo de la época en que se realizaron los muestreos. Para la sanidad de las ubres, se detectaron altos conteos de células somáticas, lo que indica que hay problemas de mastitis debido a que no se han implementado en la totalidad de las fincas las buenas prácticas ganaderas.

\section{Agradecimientos}

A los empresarios y administradores de las empresas ganaderas, sin cuya colaboración no hubiese sido posible realizar este estudio. Igualmente, a la División de Investigaciones y Extensión de la Universidad de Córdoba (Colombia), por la financiación del proyecto. 


\section{Referencias}

(1) Calderón A, García F, Martínez G. Indicadores de calidad de leches crudas en diferentes regiones de Colombia. Rev. MVZ Córdoba, 2006; 118(1): 725-737.

(2) Ministerio de la Protección Social de Colombia (MinProtección). Decreto Número 616 de 2006. Por el cual se expide el Reglamento Técnico sobre los requisitos que debe cumplir la leche para el consumo humano que se obtenga, procese, envase, transporte, comercializa, expenda, importe o exporte en el país. Disponible en: http://www.agronet.gov.co/ www/Docs agronet/2006103010449 decreto_616_28_02_06.pdf.

(3) National Mastitis Council. Laboraotry handbook on bovine mastitis. Second printing. Verona, USA. 2005.

(4) Fernández AM, Oliveira CAF. De actividade enzimática relacionada às células somáticas no leite. Revista do Instituto de Laticínios Cândido Tostes, 2007; 62: 17-25.

(5) Fox LK, Shook GE, Schultz LH. Factors related to milk loss in quarters with low somatic cell counts. J Dairy Sci, 1985; 68: 2100-2107. DOI: $\quad$ http://dx.doi.org/10.3168/jds.S00220302(85)81074-2.

(6) Ma Y, Ryan C, Barbano DM, Galton, Rudan MA, Boor KJ. Effects of somatic cell count on quality and shelf-life of pasteurized fluid milk. J. Dairy Sci, 2000; 83(2): 264-274. DOI: http://dx.doi.org/10.3168/jds.S00220302(00)74873-9.

(7) Andreatta E, Fernandes AM, Veiga dos Santos $M$, Mussarelli C, Marques MC, Gigante $M L$, Fernandes de Oliveira CA. Quality of minas frescal cheese prepared from milk with different somatic cell counts. Pesq. agropec. bras., 2209; 44(3): 320-326.

(8) Calderón A, Rodríguez V, Arrieta G, Martínez $\mathrm{N}$, Vergara O. Calidad fisicoquímica y micro- biológica de leches crudas en empresas ganaderas del sistema doble propósito en Montería (Córdoba). Rev. U.D.C.A Act. \& Div. Cient. 2012; 15(2): 399-407.

(9) Barbosa MRC, Regina BJ, Mestieri L, Felício PMA, Veiga dos Santos M. Effect of somatic cell count and mastitis pathogens on milk composition in Gyr cows. BMC Veterinary Research, 2013, 9: 67. DOI: http://dx.doi. org/10.1186/1746-6148-9-67.

(10) Cerón M, Agudelo E, Maldonado J. Relación entre el recuento de células somáticas individual o en tanque de leche y la prueba CMT en dos fincas lecheras del departamento de Antioquia-Colombia. Rev Col Cienc Pec, 2007; 20(4): 472-483.

(11) Li N, Richoux R, Boutinaud M, Martin P, Gagnaire $\mathrm{V}$. Role of somatic cells on dairy processes and products: A review. Dairy Sci. \& Technol, 2014; 94: 517-538. DOI: http://dx.doi. org/10.1007/s13594-014-0176-3.

(12) Calderón A, Arteaga MR, Rodríguez VC, Javier Arrieta GJ, Bermúdez DC, Villareal VP. Efecto de la mastitis subclínica sobre el rendimiento en la fabricación del queso costeño. Biosalud, 2011; 10(2): 16-27.

(13) Ruiz GAK, Remón DD, Ponce CP. Somatic Cell Count Dairy-Cow Milk. Rev. prod. Anim., 2014; 26 (1) 1-7. Disponible en: http://www. reduc.edu.cu/147/14/1/en/147140101-EN. pdf.

(14) Instituto Colombiano de Normas Técnicas (Icontec). Manual de métodos fisicoquímicos para el control de calidad de la leche y sus derivados. Santafé de Bogotá, Colombia, 1993.

(15) Gerber, N. Tratado práctico de los análisis de la leche y del control de los productos lácteos. España: Gráficas ROA, 1994.

(16) Association of Official Analytical Chemistry (AOAC9. 1990. Official Method of Analysis. Virginia, USA: 16a. Edición. 
(17) DeLaval. Manual de instrucciones. DeLaval International Tumba (Sweden), 2005.

(18) Romero PMH, Sánchez VJ. Evaluación de las buenas prácticas ganaderas en bovinos de carne en el centro de Caldas. Biosalud 2011; 10(1): 52-60.

(19) Consejo Nacional de Política Económica y Social. República de Colombia. Departamento Nacional de Planeación. Consolidación de la política sanitaria y de inocuidad para las cadenas láctea y cárnica. Documento Conpes 3676, 2010.

(20) Martínez M, Gómez C. Calidad composicional e higiénica de la leche cruda recibida en industrias lácteas de Sucre, Colombia. Biotecnología en el Sector Agropecuario y Agroindustrial, 2013; 11(2): 93-100.

(21) Briñez W, Valbuena E, Castro G, Tovar A, Ruiz RJ. Algunos parámetros de composición y calidad en leche cruda de vacas doble propósito en el municipio Machiques de Perijá. Estado Zulia, Venezuela. Rev. Cient. Maracaibo, 2008; 18(5): 607-617.

(22) González H, Fischer V, Rocha R, Fainé G, Stumpj W, Adeuda S. Avaliation da qualidadae do elite na bacia leitera de Pelotas, RS. Efeito dos meses do ano. Rev. Bras Zootec, 2004; 33: 1531-1543. DOI: http://dx.doi. org/10.1590/S1516-35982004000600020.

(23) Álvarez FG, Herrera HJG, Alonso BG, Barreras SA. Calidad de la leche cruda en unidades de producción familiar del sur de Ciudad de México. Arch Med Vet, 2012; 44: 237242. DOI: http://dx.doi.org/10.4067/S0301732X2012000300005.
(24) Looper M, Stokes SR, Waldner DN, Jordan ER. Managing milk composition: evaluating herd potential. New Mexico State University. 2001. Disponible en: http://aces.nmsu.edu/pubs/ d/D-104.html.

(25) Córdoba C, Naranjo J, Cuartas C. Productividad vegetal y animal bajo sistemas de pastoreo tradicional y sistemas silvopastoriles intensivos (SSPI) en el Caribe seco colombiano. Memorias VI Congreso Internacional Agroforestería para la Producción Pecuaria Sostenible. Ciudad de Panamá (Panamá); 2010, 18 p.

(26) Concejo Nacional de Mastitis (CNM). Conceptos Actuales de Mastitis Bovina. 3a Edición. 1990. (USA). 47 p.

(27) Blowey R, Edmondson, P. Control de la Mastitis en Granjas de Vacuno de Leche. Ed. Acribia, 1995. S.A. Zaragoza.

(28) Philpot N, Nickerson S. Mastitis: Ganando la lucha contra la mastitis. Babson Bros. Co. USA. 2000. 192 p.

(29) Akerstedt M, Forsback L, Larsen T, Svennersten-Sjaunja K. Natural variation in biomarkers indicating mastitis in healthy cows. J Dairy Res. 2011; 78: 88-96. DOI: http://dx.doi. org/10.1017/S0022029910000786.

(30) Andrade R, Manrique F, Peters K. Características productivas y de gestión de fincas lecheras en Boyacá. Rev. MVZ Córdoba, 2008; 13(2): 1333-1342.

(31) Alvarado L, Pardo O, Sánchez J. Evaluación de leche y/o carne de diferentes grupos raciales en el Bajo Trópico Colombiano, Ecosistema Valle Medio del Sinú. 2005. Disponible en: http://hdl.handle.net/11348/6375. 